\title{
Fatigue of survivors following cardiac surgery: Positive influences of preoperative prayer coping
}

\author{
Amy L. Ai ${ }^{1,2^{*}}$, Paul Wink ${ }^{3}$ and Marshall Shearer ${ }^{4}$ \\ 'University of Washington, Seattle, Washington, USA \\ ${ }^{2}$ University of Michigan, Ann Arbor, Michigan, USA \\ ${ }^{3}$ Wellesley College, Wellesley, Massachusetts, USA \\ ${ }^{4}$ Dexter, Michigan, USA
}

Objectives. Fatigue symptoms are common among individuals suffering from cardiac diseases, but few studies have explored longitudinally protective factors in this population. This study examined the effect of preoperative factors, especially the use of prayer for coping, on long-term postoperative fatigue symptoms as one aspect of lack of vitality in middle-aged and older patients who survived cardiac surgery.

Method. The analyses capitalized on demographics, faith factors, mental health, and on medical comorbidities previously collected via two-wave preoperative interviews and standardized information from the Society of Thoracic Surgeons' national database. The current participants completed a mailed survey 30 months after surgery. Two hierarchical regressions were performed to evaluate the extent to which religious factors predicted mental and physical fatigue, respectively, after controlling for key demographics, medical indices, and mental health.

Results. Preoperative prayer coping, but not other religious factors, predicted less mental fatigue at the 30-month follow-up, after controlling for key demographics, medical comorbidities, cardiac function (previous cardiovascular intervention, congestive heart failure, left ventricular ejection fraction, New York Heart Association Classification), mental health (depression, anxiety), and protectors (optimism, hope, social support). Male gender, preoperative anxiety, and reverence in secular context predicted more mental fatigue. Physical fatigue increased with age, medical comorbidities, and preoperative anxiety. Including health control beliefs in the model did not eliminate this effect.

Conclusions. Prayer coping may have independent and positive influences on less fatigue in individuals who survived cardiac surgery. However, future research should investigate mechanisms of this association.

Cardiac disease is the leading cause of death in the United States, while cardiac surgery is a common life-changing procedure in middle-aged and late life. Concerting preferences for treatment outcomes, however, cardiac patients tended to value quality of life equally

\footnotetext{
* Correspondence should be addressed to Amy L. Ai, PhD, Professor and Associate Dean for Research, CSW Florida State University, 2500 University Center Building-C, Tallahassee, FL 32306 (e-mail: amyai8@gmail.com).
} 
or even more than they value quantity of life (Stanek, Oates, McGhan, Denofrio, \& Loh, 2000). For older patients, absence of fatigue or tiredness, a latent indicator of vitality, is a key component of health-related quality of life (e.g., Hofer et al., 2004; Lindgren et al., 2008). Coexisting with depression, fatigue is a sensitive indicator for cardiac prognosis (Hägglund, Boman, Lundman, \& Brulin, 2008). A recent study found that preoperative use of prayer for coping (prayer coping) predicted less depression in a follow-up of patients who survived cardiac surgery, controlling for preoperative mental health, established protective factors (e.g., optimism, social support), and standardized cardiac indices (Ai, Ladd et al., 2010). Capitalizing on these findings, the current study examined the differential effect of various faith factors on fatigue, indicating low vitality, in middle-age and older patients at 30 months after surviving cardiac surgery.

\section{Vitality, fatigue, and stress impact in cardiac patient}

Arguing for a holistic, eudaimonic view of health and wellness, Ryan and Deci (2000, 2001) endorse the self-determination theory (SDT, involving experiencing vitality, or aliveness), as essential elements of human well-being, dating back to ancient West and East traditions (Ryff et al., 1998; Ryff \& Springer, 2003). Over two millennia ago, philosophers Aristotle and Laozi endorsed the virtue of wisdom as giving rise to activities cultivating the highest human good and well-being (Ai, Ladd et al., 2010; Aristotle/Oswald, trans 1962). Virtue, in this sense, refers broadly to excellence of character, full personal functioning, flourishing, and vitality, rather than merely a narrow set of moral values or happiness. The STD posits experiencing vitality (or aliveness), growth, integrity, and psychological health, as essential elements of well-being (Ryan \& Deci, 2000).

Arguing for a holistic, eudaimonic view of well-being (EWB), Ryan and Deci (2001) endorse a notion of psychological wellness, which expands the hedonic view of wellness (HWB; e.g., maximizing pleasure and life satisfaction and avoiding pain). Dating back to Western and Eastern traditions, EWB adds meaningfulness and intrinsic motivation to characteristics describing a fully functioning person (see Ryff \& Springer, 2003). Ryan and Frederick (1997) suggested an expansion of the criteria for evaluating good health by enhancing a sense of vitality from personal autonomy and relatedness to such more traditional factors as fewer physical symptoms and better health habit (e.g., not smoking, eschewing fatty diets). Stated differently, feeling of vitality may be a marker of positive health and a state of mind that has beneficial health ramifications. In medical research, one aspect of vitality can be operationalized in terms of an absence of fatigue symptoms. Although not necessarily being direct opposite, the two constructs are bound to be negatively related.

Conceptualizing absence of fatigue in terms of vitality has the distinct advantage of tying together medical research focused on pathology with findings from the growing field of positive psychology. Further, positive health concepts are promoted in the new era of patient-centred collaborative care (Ai, Rollman, \& Berger, 2010). The significance of investigating its behavioural predictors lie in that fatigue is a major component of 'vital exhaustion', a clinical syndrome among patients with advanced coronary heart diseases (CHDs; Appels \& Mulder, 1988). Feeling of fatigue shares characteristics of energy overload with chronic fatigue syndromes (De Meirleir \& McGregory, 2003; Jason et al., 1995). Exhaustion, or cardiac fatigue, may be a specific form of this syndrome (Ai, Peterson, Bolling, \& Rodgers, 2006) as it predicts CHD and cardiac events in healthy 
persons (Appels \& Mulder, 1988) and is related to impaired heart status in patients, including those undergoing cardiac procedures (Kop et al., 1993; Smith, Gidron, Kupper, Winter, \& Denollet, 2009). Exhaustion has been found to be reversible in older patients of cardiac diseases, but recovery is less likely to occur in those with depression, poor self-rated health, and poly-medication use (Whitson, O'Mare, Chaves, Zakai, \& Newman, 2011).

Little is known about the protective predictors of vitality among older patients undergoing cardiac surgery but their poor prognosis, including cardiac fatigue, has been linked with distress (Lindgren et al., 2008) or negative mood (Barth, Schumacher, \& Herrmann-Lingen, 2004; Carroll, Phillips, \& Hunt, 2007; Pignay-Demaria, Lesperance, Demaria, Frasure-Smith, \& Perrault, 2003). These findings are important because cardiac operation, a stressful event in middle age and late life, can induce perioperative negative moods, including persistent depression and anxiety (PignayDemaria et al., 2003). Reviews of prospective cardiac-surgery research found that preoperative anxiety and depression predicted psychological maladjustment, as well as postoperative cardiac events (e.g., unstable angina, acute myocardial infarction (MI), and death; Duits, Boeke, Taamms, Passchier, \& Erdman, 1997; Pignay-Demaria et al., 2003). Clearly, investigation of protectors for cardiac vitality must control stress-related risk factors.

\section{Motivating effect of prayer coping and the potential mediation of control beliefs}

A growing number of studies have demonstrated the protective effect of religiousness on the risk of coronary disease and poor health in general (Koenig, McCullough, \& Larson, 2001; Miller \& Thoresen, 2003; Oman \& Thoresen, 2005). In patients with advanced cardiac conditions requiring surgery, intrinsic and inner-experience related such factors (e.g., prayer, belief strengths) were shown to have greater positive effects than mere church attendance (Ai, Park, Huang, Rodgers, \& Tice, 2007; Contrada et al., 2004; Oxman, Freeman, \& Manheimer, 1995). Our previous research found that prayer predicted fewer postoperative complications in cardiac surgery patients (Ai, Wink et al., 2009), lower levels of depression and anxiety 1 month after operation (Ai, Peterson et al., 2007), and ameliorated distress assessed 1 year after operation (Ai, Dunkle, Peterson, \& Bolling, 1998). In this view, prayer coping can be seen as a self-determining health-related motivating behaviour. We expected that in the present study prayer coping would promote a sense of vitality based on a sense of selfdetermination and, therefore, buffer against cardiac surgery related stress (Ai, Ladd et al., 2010).

This direct potential role in cardiac health may arguably lie in the very nature of prayer coping itself. A 17th-century rabbi indicated prayer as God's gift of love (Begun, 1997). Similarly, William James (1901/1958) defined prayer as 'inward communion or conversation with the power recognized as divine', be it God or the universe. Prayer coping, in his view, is 'an intercourse, a conscious and voluntary relation, entered into by a soul in distress ... ' (p. 352). In the face of life-altering operations, engaging in prayer, a practice that expands self-boundary to include a transcendent being, can serve as an important coping resource for patients dealing with perioperative distress, especially when other forms of control are elusive (Contrada et al., 2004; Levin, 2004). Through perceived connection to eternity, prayer in adversity could promote meaning in life, spiritual love, and a sense of transcendence, as well as inspiring and strengthening the will to survive (Ai, Peterson, Bolling, \& Koenig, 2002; Levin, 2004). Because of its 
motivating nature, prayer may particularly benefit vitality-related well-being in individuals facing drastic life challenges (Ai, Ladd et al., 2010; Ai, Peterson et al., 2002; Cohen et al., 2005; Levin, 2004).

Faith-based coping, including prayer, can also be a source of empowerment and promote an internal locus of control among distressed individuals (McIntosh \& Spilka, 1990). Indeed, our preliminary finding using preoperative data from a subsample of participants in the current study found that the preoperative intent to use prayer coping predicated internal control right before operation (Ai, Peterson, Rodgers, \& Tice, 2005). Further, the literature has associated perceived control with fewer cardiac events among individuals recovering from heart surgery (Helgeson \& Fritz, 1999), less physiological distress of the circulation system (Weinstein, Quigley, \& Mordkoff, 2002), and less depression and anxiety in patients with heart disease, acute MI, and heart failure (Moser et al., 2009). Based on the findings in the three-way connections (prayer - cardiac outcomes, prayer - internal control, and internal control - outcomes), the present analyses were also used to explore the potential mediation of perceived control on the prayer - fatigue connection, after controlling for key confounders. However, the salutary role of sense of control in outcome of clinical patients has not always been consistent (Astin, Shapiro, Lee, \& Shapiro, 1999). We therefore tested this uncertain association in post-hoc analyses.

\section{The present study}

In this study we examined the effects of preoperative use of prayer coping and other faith factors on long-term vitality, operationalized as absence of clinical mental and physical fatigue symptoms (Ai, Peterson et al., 2006; Chalder et al., 1993). Based on presented theory and evidence (Ai, Ladd et al., 2010; Ai, Peterson et al., 2005), we hypothesized that using prayer for coping would contribute to lower mental fatigue, but not physical fatigue, at the 30-month follow-up of cardiac surgery patients (Ai, Peterson et al., 2005). Specifically, we first controlled known key confounders, including demographics, major cardiac indices and medical comorbidities, mental health indicators, and protective factors such as optimism and social support.

Besides prayer coping, we also included in two hierarchical regressions a variety of faith factors, positive and negative religious coping behaviours, public, private, and subjective religiousness, and the sense of reverence experienced in religious and secular settings (Ai, Ladd et al., 2010). The sense of reverence was broadly defined as a deep feeling or attitude of deep respect, love, awe, and sublime, as for something sacred (Ai, Wink et al., 2009). Based on an earlier report (Ai, Ladd et al., 2010), however, we did not expect other faith factors to have a similar salutary effect on postoperative fatigue. In the last step of regression models, we used trimmed models as the final outcome to remove the influence of over-parameterization with only significant and near significant predictors included, due to the high ratio of predictors to cases. Finally, aspects of control beliefs were explored to evaluate their potential mediation in the prayer - fatigue connection. According to Baron and Kenny (1986), if the impact of predictors on outcomes is reduced to zero after controlling for a correlated mediator, then the latter explains the indirect effect of the former. 


\section{Method}

\section{The sample}

Participants were survivors after cardiac surgery used in our previous research (Ai, Ladd et al., 2010). Using a mailed survey, we recruited patients who underwent cardiac surgery 30 months earlier and participated in a two-wave preoperative survey supported by a grant from the National Institutes of Health (Ai, Peterson et al., 2002). All of patients received non-emergent cardiac surgery (e.g., coronary bypass graft or CABG, aneurysm repairs, valve repair or replacement) at the Section of Cardiac Surgery, the University of Michigan Health Systems (UMHS, Ann Arbor). A cross all these operations a heartlung bypass machine was used. As a specialty centre for valve surgery in heart failure management, UMHS had many more severe cases referred from other hospital settings, including more advanced heart conditions, especially congestive heart failure (CHF), than would be found in typical surgery units. Therefore, many of the patients returned to their local primary care after operation.

For the current 30-month follow-up, funded by different foundations, we were able to locate and consented 262 individuals of 426 patients who completed the previous twowave preoperative study, to participate in the follow-up survey (66\%). Attrition at this follow-up was mainly due to mortality, outdated contact data, or refusal to participate. All participants offered new consents for the follow-up. Average age of the current sample was $62(S D=11.88)$, while average education was 14 years $(S D=3.43)$. The majority was Caucasian (92\%), Judeo-Christian 86\%), male (62\%), and currently married or living with somebody (77\%).

\section{Procedure}

Initial preoperative data were collected in a project funded by the NIH; cardiac surgeons delivered the information package about this study, and nurses helped with identifying eligible patients. Subject eligibility criteria were: (1) aged $>35$ years, (2) scheduled for non-emergency, non-transplant open-heart surgery, (3) English proficiency, (4) cognitively and physically capable of providing consent, (5) informed consent actually provided, and (6) permission by the surgeon. The preoperative data for participants were collected from that study by trained interviewers in this previous project (Ai, Peterson et al., 2002).

At the initial assessment, there were no statistical differences in demographics between consenters and non-consenters. After consent was obtained, trained interviewers collected information on socio-demographics, medical comorbidities, mental health symptoms, and religious factors through the first wave personal assessment, approximately 2 weeks prior to surgery. Then, they conducted telephone interview in the second wave to assess potential psychosocial protectors (e.g., optimism, hope, social support) 2 days preoperatively. The standardized medical, cardiac, and surgical information was obtained from the Society of Thoracic Surgeons' national database (STS) and maintained at UM Heart Center (Ai, Peterson et al., 2002). For the new study, research assistants called patients based on the contact information collected through the previous study and available in the STS database. They assessed mental and physical fatigue, as well as types of bealth control beliefs. In order to ensure quality, a computerized double entry system was used to record survey data obtained. 


\section{Measures}

Our dependent variable was assessed with the 14-item Fatigue Scale (Chalder et al., 1993), measuring long-term postoperative physical and mental fatigue (seven items each). Participants responded to individual items on a 4-level scale (mental fatigue: $M=$ $12.71, S D=2.77$, Cronbach's alpha $(\alpha)=.83$; physical fatigue: $M=17.27, S D=3.81$, $\alpha=.89)$.

Control as a potential mediator was assessed at the 30-month follow-up with three subscales of the 18-item Multidimensional Health Locus of Control scale (HLC Form A; Wallston, Wallston, \& DeVellis, 1978). Items were scored on a 6-point scale and assessed three control dimensions: Internality (or internal HLC; $M=25.20, S D=5.39, \alpha=$ .92), Powerful Others Externality (or powerful others HLC; e.g., physician and health professionals; $M=22.31, S D=5.68, \alpha=.75$ ), and Chance Externality (or chance HLC; $M=16.36, S D=5.55, \alpha=.67)$.

The main independent variables consisted of measures of several faith factors all of which were administered preoperatively. The 3-item Use of Prayer for Coping index assesses the experiential, appraisal, and intentional aspects of prayer coping (Ai, Peterson et al., 2002). Two weeks before cardiac surgery, patients were asked the extent to which they agreed with statements on importance of prayer, appraisal for its efficacy, and intent to use it for coping with surgery on a 4-point scale $(M=3.35, S D=.80, \alpha=.89)$.

We measured religious/spiritual coping styles with the 14-item Brief Religious/Spiritual Coping scale (R-cope; Pargament, Smith, Koenig, \& Perez, 1998), scored on a 4-point scale and assessing two coping styles: positive (e.g., spiritual connection; $M=11.90, S D=6.44, \alpha=.94$ ) and negative (e.g., spiritual discontent; $M=1.23, S D$ $=2.59, \alpha=.86$ ). We also measured religiousness with the 11-item Religiosity Scale (Chatters, Levin, \& Taylor, 1992), which assesses: public religiosity $(M=11.22, S D=$ $4.73, \alpha=.87)$, private religiosity $(M=10.16, S D=3.84, \alpha=.78)$, and subjective religiosity $(M=6.00, S D=1.73, \alpha=.88)$.

Further, sense of reverence was assessed with the sum of Yes/No answers to a checklist of eight circumstances in response to the question: 'Under what conditions do you feel reverent?' The purpose of this instrument was to capture two contexts (4-item each) in which individuals experienced sacred feelings (Ai, Wink et al., 2009): religious (e.g., attending religious services; $M=2.71, S D=1.32, \alpha=.72$ ) and secular (e.g., sightseeing or being in nature; $M=2.79, S D=1.28, \alpha=.68$ ).

Three measures administered 2 days preoperatively were used to control for known protective factors (Ai, Ladd et al., 2010). The 12-item Multidimensional Scale of Perceived Social Support (MSPSS; Zimet, Powell, Farley, Werkman, \& Berkoff, 1990) measured perceived support from family, friends, and significant others, with individual items scored on a 4-level scale $(M=62.21, S D=7.80, \alpha=.89)$. The 12-item Life Orientation Test (LOT; Scheier \& Carver, 1985) assessed optimism. Patients were asked the extent to which they agree with each statement in the prior month on a 5-level scale ( $M=22.38, S D=4.27, \alpha=.73)$. Snyder et al.'s (1991) 12-item Hope scale assessed hopefulness they felt in the prior month on a 5-level scale $(M=31.12, S D=4.10$, $\alpha=.81$ ).

We also assessed multiple preoperative risk factors 2 weeks prior to operation, including depression, using the 20-item Center for Epidemiologic Studies Depression Scale (CES-D; Radloff, 1977) on a 4-point scale ( $M=12.63, S D=9.88, \alpha=.88)$, anxiety, using the 20-item Trait Anxiety Inventory (STAI Form X-2), part of the State-Trait Anxiety Inventory (Spielberger, 1983) on a 4-point scale $(M=36.57, S D=10.84, \alpha=.91)$, and self-reported medical comorbidities with the sum of Yes/No answers to a checklist of 
17 chronic conditions (Ai, Peterson et al., 2002), commonly seen in geriatric clinics (e.g., diabetes, arthritis; $M=2.65, S D=2.63$ ). Demographic information included: age (years), gender $(0=$ male, $1=$ female $)$, race $(0=$ non-White, $1=$ White $)$, and marital status $(0=$ all other, $1=$ married with spouse present or living with significant other.

\section{Objective medical data}

We obtained key cardiac indices assessed 2-4 weeks preoperatively, from the STS national database. Left ventricular ejection fraction (LVEF) indicates the percentage of blood emptied from ventricle at the end of cardiac contraction, obtained from angiography (lower rates indicating poor function; $M=52.58, S D=12.95$ ). New York Heart Association (NYHA) Classification is the highest association level leading to episode of hospitalization and/or procedure (lower levels indicating better function; Levels: $\mathrm{I}=39.3 \%, \mathrm{II}=34.7 \%$, III $=23.7 \%, \mathrm{IV}=1.5 \%$ ). $\mathrm{CHF}$ is defined as whether, within 2 weeks prior to procedure, a physician had diagnosed $\mathrm{CHF}(\mathrm{NO}=54 \%$, YES $=46 \%)$ by one of the following: paroxysmal nocturnal dyspnea (PND); dyspnea on exertion (DOE) due to heart failure; or chest $\mathrm{x}$-ray (CXR) showing pulmonary congestion. Preoperative cardiac intervention is defined as whether the patient had undergone any previous cardiovascular intervention preoperatively, either surgical or non-surgical, which may include those done during the current admission (e.g., thrombolytic therapy for cardiac indications; $\mathrm{NO}=70 \%$; YES $=30 \%$ ).

\section{Statistical analyses}

Chi-square and $t$-tests were conducted for attrition analyses to reveal differences between study completers and dropouts at the follow-up. To evaluate the direct effects of religious factors in our hypothesis, above and beyond those of existing predictors in the literature, two hierarchical regression analyses were performed on the long-term follow-up data of mental and physical fatigue, respectively, using SPSS18. These selected predictors were entered following the pre-planned steps: (1) demographics, (2) four STS cardiac indices, (3) self-reported medical comorbidities, psychological symptoms (depression or anxiety), and protectors (optimism, hope, and social support), (4) major religious factors (three-factor religiousness, use of prayer for coping, sense of reverence, and positive/negative R-cope), and (5) a trimmed model with only significant and near significant predictors included. This final step was taken to ascertain if the statistical significance in Step 5 was inflated by a higher ratio of predictors to cases (overparameterization) in Steps 3 and 4 regression models. Finally, we performed post-boc analyses to test whether our three measures of health control beliefs mediated the prayer-fatigue relationship. All analyses were performed as two-tailed with significance level set at $p<.05$. We inspected collinearity statistics, using a conservative value of variance inflation factors (VIFs; 4).

\section{Results}

\section{Bivariate correlations}

Attrition analyses revealed that there were no differences in age, most cardiac indices, depression, anxiety, and any faiths factors between study completers and dropouts. 
However, compared with the dropout, study completers tended to have fewer medical comorbidities, to have previous cardiovascular intervention, and to have a living partner $(p s<.01)$. The former also had greater proportions in men, those who were more optimist and hopeful, and those who had perceived greater preoperative social support $(p s<.05)$.

Table 1 presents bivariate correlations. The two dependent variables, follow-up mental and physical fatigue were moderately inter-correlated. Mental, but not physical, fatigue was correlated inversely with using prayer for coping. Among control variables, both forms of fatigue were significantly and inversely correlated with marital status and preoperative optimism. Only physical fatigue was associated with hope. Both forms of fatigue were positively correlated with medical comorbidities, depression, and anxiety. Physical fatigue was additionally correlated positively with age and negatively with internal control. Prayer coping was correlated positively with all religious factors, ranging from a significant but low association with secular reverence to a strong association with subjective religiousness. In addition, prayer coping was inversely related to control attributed to power others. Secular reverence was correlated with all other religious factors, ranging from a moderate positive association with religious reverence to a significant but low-magnitude link with negative religious coping.

\section{Mental fatigue}

Table 2 presents hierarchical regression analyses predicting mental fatigue at follow-up. Predictors were entered into the equation following the predetermined five steps. In Step 1, among demographics, marital status significantly predicated 30-month mental fatigue, accounting for about $3 \%$ of the variance. Those who lived without a partner were more likely to experience mental fatigue than their counterparts who lived with a spouse or living with somebody. In Step 2, the association persisted, while none of the four added cardiac indices in the STS were predictive. The $R^{2}$ change was not significant, with both Steps 1 and 2 models being not significant. In Step 3, entry of preoperative selfreported medical comorbidities and psychosocial factors diminished the role of marital status, but gender became a significant predictor. Among new factors entered, anxiety predicted mental fatigue, while medical comorbidities also had a marginal positive effect. Male and those with poor self-reported health and/or with greater anxiety were more likely to report mental fatigue. The $R^{2}$ change, accounting for an additional $12.4 \%$ of the variance from Step 2, was significant, and so was the overall model.

In Step 4, entry of religious factors did not alter most associations but reduced the influence of self-reported medical comorbidities to a marginal level. Among new factors, preoperative use of prayer for coping was inversely associated with mental fatigue, whereas secular reverence was related positively. The $R^{2}$ change, adding additional $5.6 \%$ of the variance from Step 3, was marginally influential $(p=.08)$, and the overall model remained significant. This model explained over one fifth of the variance. In Step 5, the trimmed model was performed to detect over-parameterization impacts, using predictors with at least near significant effects. The results remained essentially the same, including four significant predictors: gender $(p<.05)$, preoperative anxiety $(p<.001)$, prayer coping $(p<.05)$, and secular reverence $(p<.01)$, and one with only a marginal influence: medical comorbidities $(=.05)$. This final model $[F(5, N=195)=$ $\left.8.032, p<.001, R^{2}=.174\right]$ explained over one sixth of the variance in mental fatigue. In sum, patients who were male, and those who preoperatively reported greater anxiety or 


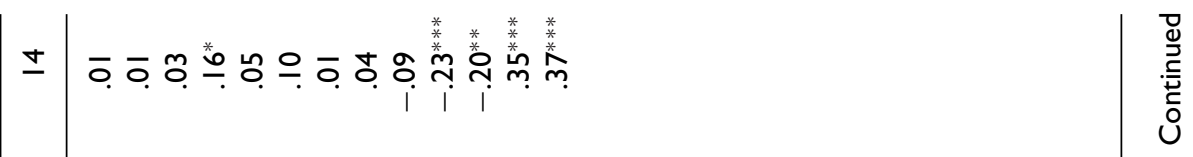

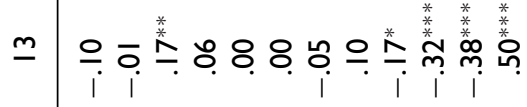



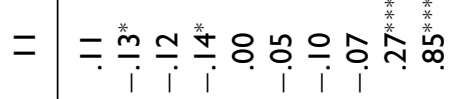

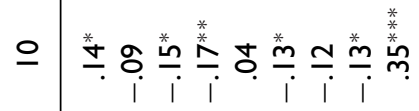

$\sigma \quad \stackrel{*}{\stackrel{*}{*}} \stackrel{*}{m} \underset{i}{\stackrel{*}{m}} \underset{i}{\stackrel{*}{n}} \stackrel{\stackrel{*}{m}}{\rightarrow}=\underset{i}{g} \underset{i}{\stackrel{*}{m}}$

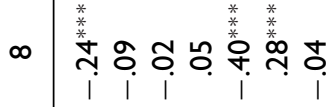

$\wedge \quad$ 울 $\stackrel{*}{m}$ 우 으 웅

- 8 o 0 \%

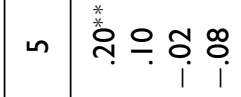

$+\underset{i}{\stackrel{*}{*}} \stackrel{\substack{* \\ \infty}}{\infty}:$

$m$ 호. 으.

$\sim \bar{i}$

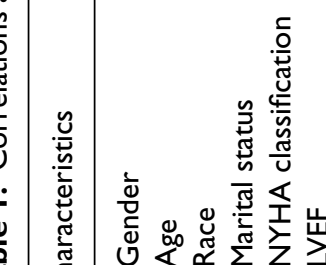

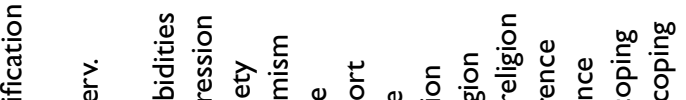

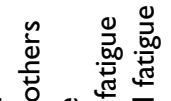

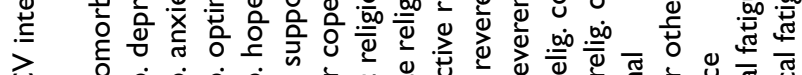

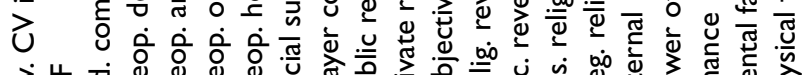




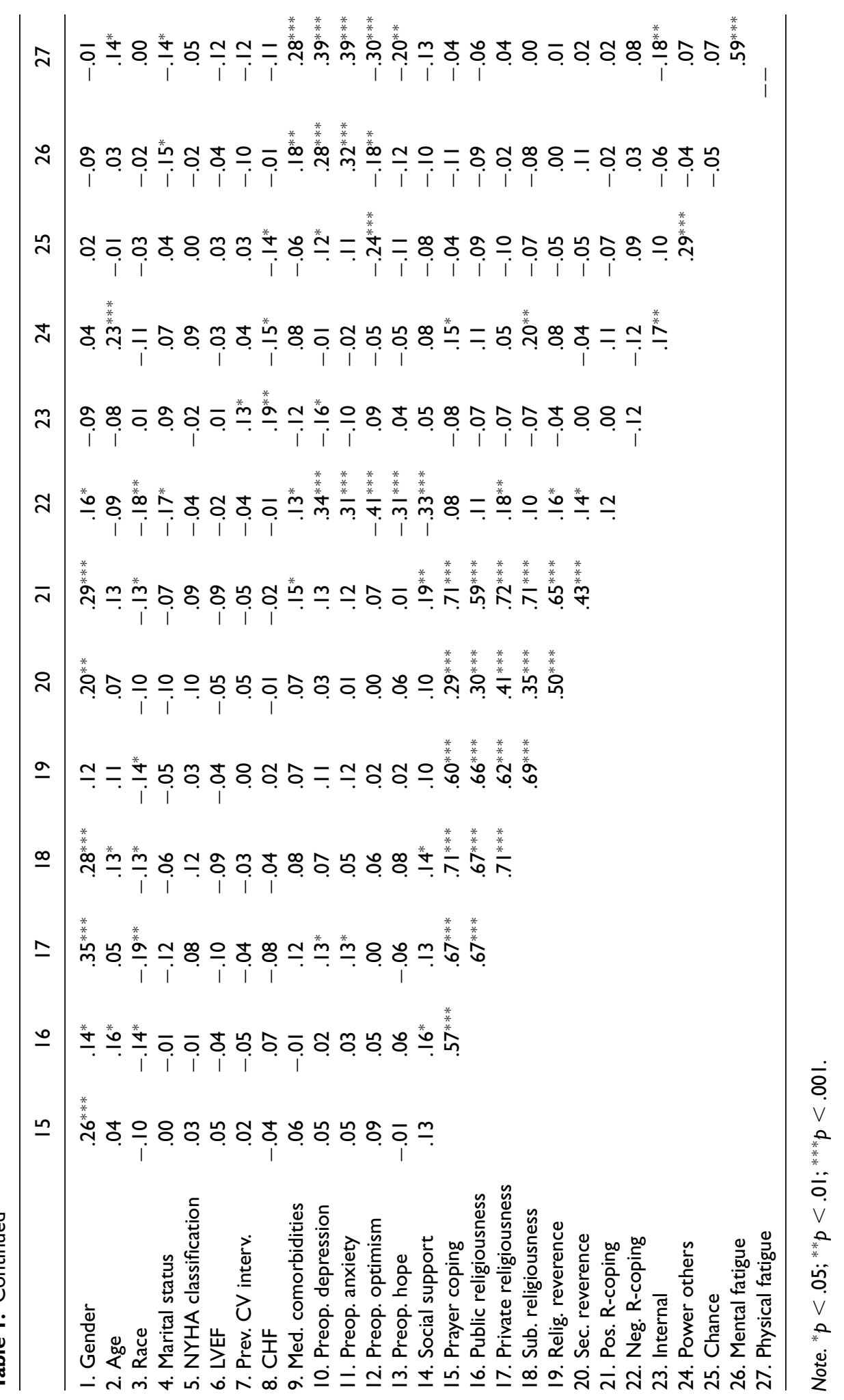


Table 2. Hierarchical regression analysis predicting mental fatigue at the follow-up

\begin{tabular}{|c|c|c|c|c|c|}
\hline Gender & $-.113(.065)$ & $-.115(.068)$ & $-.174(.066)^{*}$ & $-.157(.07 \mid)^{*}$ & $-.146(.066)^{*}$ \\
\hline Age & $.044(.003)$ & $.034(.003)$ & $.057(.003)$ & $.060(.003)$ & \\
\hline Race & $-.009(.118)$ & $-.007(.118)$ & $.057(.116)$ & $.047(.119)$ & \\
\hline Marital status & $-.154(.077)^{*}$ & $-.148(.077)^{*}$ & $-.108(.075)$ & $-.088(.075)$ & \\
\hline \multicolumn{6}{|l|}{ Step I $F=1.69 \mid(\mathrm{d} f=4), R^{2}=.030$} \\
\hline NYHA classification & & $-.029(.042)$ & $-.013(.040)$ & $-.027(.039)$ & \\
\hline LVEF & & $-.068(.003)$ & $-.05 \mathrm{I}(.002)$ & $-.019(.003)$ & \\
\hline Previous CV intervention & & $-.086(.07 \mathrm{I})$ & $-.062(.068)$ & $-.077(.068)$ & \\
\hline $\mathrm{CHF}$ & & $-.007(.069)$ & $.014(.066)$ & $.008(.066)$ & \\
\hline \multicolumn{6}{|l|}{ Step $2 F=1.194(d f=8), R^{2}=.043$} \\
\hline Medical comorbidities & & & $.143(.015)$ & $.135(.015)$ & $.137(.015), p=.05$ \\
\hline Preoperative depression & & & $-.056(.123)$ & $-.050(.122)$ & \\
\hline Preoperative anxiety & & & $.325(.109)^{*}$ & $.341(.109)^{* *}$ & $.292(.062)^{* * *}$ \\
\hline Preoperative optimism & & & $-.017(.07 \mathrm{I})$ & $-.006(.073)$ & \\
\hline Preoperative hope & & & $-.029(.070)$ & $-.050(.07 I)$ & \\
\hline Social support & & & $019(.05 \mathrm{I})$ & $-.010(.053)$ & \\
\hline \multicolumn{6}{|l|}{ Step $3 F=2.916(d f=14),{ }^{* * *} R^{2}=.164$} \\
\hline Prayer coping & & & & $-.199(.059)^{*}$ & $-.160(.040)^{*}$ \\
\hline \multicolumn{6}{|l|}{ Public religiousness } \\
\hline Private religiousness & & & & $.117(.013)$ & \\
\hline Subjective religiousness & & & & $-.043(.030)$ & \\
\hline Religious reverence & & & & $.020(.037)$ & \\
\hline Secular reverence & & & & $.177(.027)^{*}$ & $.197(.025)^{* *}$ \\
\hline Positive religious coping & & & & $-.008(.054)$ & \\
\hline Negative religious coping & & & & $-.102(.093)$ & \\
\hline \multicolumn{6}{|l|}{ Step $4 F=2.557(d f=22),{ }^{* * *} R^{2}=.220$} \\
\hline \multicolumn{6}{|l|}{ The final trimmed model } \\
\hline Step $5 F=8.032(d f=5),{ }^{* * *} R^{2}=.174$ & & & & & \\
\hline
\end{tabular}

Note. ${ }^{*} p<.05 ;{ }^{* *} p<.01 ;{ }^{* * *} p<.001$.

secular reverence were more likely to experience mental fatigue. Those who indicated using prayer for coping preoperatively had less mental fatigue at follow-up.

Post-hoc analyses were performed to explore whether sense of control mediated the relationship between fatigue and significant predictors. This additional step did not alter the existing pattern, likely due to the lack of correlation between control variables and dependent, as noted in Table 1 . The $R^{2}$ change was not significant. All VIFs in above steps were below 4, except for depression that was slightly above 4 .

\section{Physical fatigue}

Table 3 presents hierarchical regression analyses predicting physical fatigue at followup. Predictors were entered into the equation following the same steps. In Step 1, among demographics, marital status significantly predicted 30-month physical fatigue, accounting for about $4.2 \%$ of the variance. Those who lived without a partner were more likely to experience physical fatigue than their counterparts who lived with a spouse or living with somebody. In Step 2, these associations persisted, while none of the four added cardiac indices in the STS were predictive. The $R^{2}$ change was not significant. Neither of the first two models was significant. In Step 3, entry of preoperative selfreported medical comorbidities and psychosocial factors diminished the role of marital status, but both age and gender become significant predictors. Among new factors entered, medical comorbidities and anxiety predicted physical fatigue. Older and male patients and those with poor self-reported health and with more anxiety were more 
Table 3. Hierarchical regression analysis predicting physical fatigue at the follow-up

\begin{tabular}{|c|c|c|c|c|c|}
\hline Variable & Step I beta (SE) & Step 2 beta (SE) & Step 3 beta (SE) & Step 4 beta (SE) & Step 5 beta (SE) \\
\hline Gender & $-.061(.067)$ & $-.085(.070)$ & $-.164(.063)^{*}$ & $-.161(.069)^{*}$ & $-.129(.06 \mathrm{I})^{*}$ \\
\hline Age & $.129(.003)$ & $.114(.003)$ & $.155(.002)^{*}$ & $.166(.003)^{*}$ & $.162(.003)^{*}$ \\
\hline Race & -.011 (.122) & $-.008(.12 \mathrm{I})$ & $.090(.111)$ & $.073(.115)$ & \\
\hline Marital status & $-.149(.079)^{*}$ & $-.149(.080)^{*}$ & $-.082(.072)$ & $-.078(.073)$ & \\
\hline \multicolumn{6}{|l|}{$\begin{array}{l}\text { Step I } F=2.363(\mathrm{df}=4) \text {, } \\
\quad R^{2}=.042\end{array}$} \\
\hline NYHA classification & & $-.027(.043)$ & $.002(.038)$ & $-.007(.038)$ & \\
\hline LVEF & & $-.087(.003)$ & $-.045(.002)$ & $-.030(.002)$ & \\
\hline Prev. CV intervention & & $-.073(.073)$ & $-.036(.065)$ & $-.044(.066)$ & \\
\hline $\mathrm{CHF}$ & & $-.092(.07 I)$ & $-.048(.063)$ & $-.038(.064)$ & \\
\hline \multicolumn{6}{|l|}{$\begin{array}{l}\text { Step } 2 F=1.850(d f=8) \\
\quad R^{2}=.065\end{array}$} \\
\hline Medical comorbidities & & & $.132(.014)$ & $.122(.014)$ & $.161(.015)^{*}$ \\
\hline Preoperative depression & & & $.150(.117)$ & $.167(.119)$ & \\
\hline Preoperative anxiety & & & $.240(.104)^{*}$ & $.238(.106)^{*}$ & $.400(.064)^{* * *}$ \\
\hline Preoperative optimism & & & $-.087(.068)$ & $-.109(.07 I)$ & \\
\hline Preoperative hope & & & $-.049(.067)$ & $-.058(.069)$ & \\
\hline Perceived social support & & & $.014(.049)$ & $-.013(.052)$ & \\
\hline \multicolumn{6}{|l|}{$\begin{array}{c}\text { Step } 3 F=6.216(d f= \\
14),{ }^{* * *} R^{2}=.295\end{array}$} \\
\hline Prayer coping & & & & $-.061(.057)$ & \\
\hline Public religiousness & & & & $-.132(.009)$ & \\
\hline Private religiousness & & & & $.118(.013)$ & \\
\hline Subjective religiousness & & & & $.038(.029)$ & \\
\hline Religious reverence & & & & $.018(.036)$ & \\
\hline Secular reverence & & & & $.033(.026)$ & \\
\hline Positive religious coping & & & & $-.029(.053)$ & $.052(.093)$ \\
\hline Negative religious coping & & & & $-.126(.090)$ & \\
\hline \multicolumn{6}{|l|}{$\begin{array}{c}\text { Step } 4 F=4.222(d f= \\
22),{ }^{* * *} R^{2}=.317\end{array}$} \\
\hline \multicolumn{6}{|l|}{ The final trimmed model } \\
\hline $\begin{array}{l}\text { Step } 5 F=12.330(d f= \\
5),{ }^{* * *} R^{2}=.242\end{array}$ & & & & & \\
\hline
\end{tabular}

Note. ${ }^{*} p<.05 ;{ }^{* *} p<.01 ;{ }^{* * *} p<.001$.

likely to report physical fatigue. The $R^{2}$ change, accounting for an additional $23 \%$ of the variance from Step 2, was significant, and so was the overall model.

In Step 4, entry of religious factors did not alter most patterns but reduced the influence of self-reported medical comorbidities to a marginal level. None of the religious factors contributed significantly to the model. The $R^{2}$ change was not significant. This model explained about one third of the variance. In Step 5, the trimmed model was performed to detect over-parameterization impacts, using predictors with at least near significant effects. The result on influential factors remained essentially the same, except that the role of medical comorbidities became significant. The four significant predictors include gender $(\phi<.05)$, medical comorbidities $(p<.05)$, and preoperative anxiety $(p<.001)$. The effect of negative R-cope completely vanished, indicating the impact of over-parameterization. This final model $\left[F(5, N=198)=12.330, p<.001, R^{2}=.242\right]$ explained nearly a quarter of the variance in physical fatigue. In sum, patients who were male or older and those who had poor health or reported greater preoperative anxiety were more likely to experience physical fatigue at the 30-month follow-up.

Post-boc analyses were performed to explore whether there was a mediating effect of control factors, which did not alter existing relationships. No control belief was 
predictive of fatigue, though the association between internal control and physical fatigue was at a marginal level $(p<.10)$. The $R^{2}$ change was not significant. All VIFs were below 4 , except that depression that was located between medical comorbidities and anxiety, slightly above 4 .

\section{Discussion}

Despite ample research on the role of religious involvement in health and aging, there has been a dearth of prospective studies on the long-term effect of spiritual coping on patients who survived cardiac surgery, controlling for standardized cardiac indices. In particular, little is known about the influence of religious coping on the postoperative EWB, such as feeling energetic, alive, or vitally active; all positive aspects of functioning that can be undermined by the existential threat posed by the life-changing nature of cardiac surgery. The buffering effect of prayer coping on fatigue replicates a role of prayer in HWB (less depression), obtained previously using date from the same study (Ai, Ladd et al., 2010). However, the present study is also ground breaking by casting light on the independent positive effect of preoperative prayer coping on the long-term EWB (greater vitality).

Specifically, prayer coping was inversely associated with mental fatigue in bivariate analyses, multivariate analyses showing its direct effect above and beyond key confounders, and in the final trimmed model. The salutary role of prayer coping, compared to absent effects of other faith factors, may be partly attributable to its inspiring and motivating nature in the face of challenges (Ai, Peterson et al., 2002; Cohen et al., 2005; James, 1901/1958; Levin, 2004). In the face of life-altering events, engaging in prayer, a popular form of coping resource among the elderly, can be a unique internal spiritual resource for patients dealing with perioperative distress when other forms of personal control are elusive (Contrada et al., 2004; Levin, 2004). This usage may energize individuals by promoting a sense of a perceived deep connection between the self, others, and a higher power (Ladd \& Spilka, 2002, 2006). Its motivational quality in times of adversity thus resides in the extended boundaries of the self to embrace transcendence (Ladd \& Spilka, 2002; Ai, Tice et al., 2011). In turn, the self-determinant action can enhance an individual's sense of meaning in life (Levin, 2004), and result in tangible changes in the way a person thinks and behaves and, as a result, enhance vital involvement in life (Ladd et al., 2007).

However, the same effect was not true of other types of religious coping, public, private, and subjective religiosity, and religious reverence. The differential finding may lie in the fact that preoperative use of prayer is an event-specific, energizing coping behaviour, whereas the other measures of religiousness used in the study were not. Our study thus helps fill a void in prospective research on religion and health, the need outlined by an NIH panel for understanding the multidimensional nature of religious involvement and its impact (Oman \& Thoresen, 2005). The long-term effect of prayer coping, although modest, is not trivial, given it is based on prospective data and remains significant after controlling for a slew of control measures including cardiac function, CHF, depression, control, optimism, and social support. Our main finding supports that of Wilks and Vonk (2008) who, using the same measure of prayer coping, found a salutary effect of this behaviour, but other factors of general religiousness, on mental health (resilience) among Alzheimer's caregivers. The differential effect of various religious beliefs and practices on cardiac health outcomes argues for the need to pay more 
attention to the positive influence of this event-specific type of religious involvement rather than merely postulating a beneficial effect of intrinsic religiousness or general religious involvement.

Further, we previously found that optimism protected against both postoperative depression and anxiety among patients survived cardiac surgery (Ai, Ladd et al., 2010). Nevertheless, by failing to demonstrate mediation of any optimistic expectation (i.e., health control beliefs and positive outlook on life), the current study supports the notion that prayer coping exercises a direct effect on postoperative mental fatigue in its own right. The lack of influence of health control beliefs is contrary to many other findings on the positive influence of health control beliefs (e.g., Moser et al., 2009; Weinstein et al., 2002). The inconsistency may also lie in the long-term follow-up period between baseline and follow-up given that control is an event-specific attitude (control) and in our study it was assessed preoperatively. Alternatively, the difference in findings may be related to the type of control measures being used.

While we failed to reveal mechanisms underlying the prayer-outcome connection, the salutary effect of prayer is associated with other psychological mechanisms (e.g., will power, inspiration, or survival intention in relation to positive emotions) that bridge the mind-body connection (Ai, Peterson et al., 2002). Alternatively, prayer coping in its very nature (see Begun, 1997; James, 1901/1958; Levin, 2004) and in its event-specific context may result in strong sense of intrapersonal connectedness in patients facing adversity. In non-cardiac studies, prayer's beneficial effects was indeed mediated through perceived spiritual support that showed similar influence as social support (Ai, Tice, Lemieux, \& Huang, 2011). These underlying mechanisms warrant investigation using larger samples and advance statistical tools such as structural equation modelling (Ai, Tice et al., 2011).

Still other possibilities might include prayer's potential physiological consequences. For example, research has linked exhaustion with excessive stress-sensitive biomarkers such as cortisol (Koertge et al., 2002) and interleukin-6 (Janszky, Lekander, Blom, Georgiades, \& Ahnve, 2005) in women with CHD. Kwaijtaal et al. (2000) found low macrophage migration inhibitory factor, a protein secreted by immune cells and the pituitary gland, in exhausted patients following percutaneous coronary intervention, indicating a hypoactivity of the hypothalamic-pituitary-adrenocortical axis. If our finding on the link between prayer and mental fatigue is replicated, further examination may explore psycho-immuno-physiological correlates of this link in a potentially fruitful dimension.

Although prayer coping had a direct, unmediated effect on mental fatigue, it had no significant influence on physical fatigue. This differential finding points to the need to assess the two types of fatigue or lack of vitality among cardiac patients separately. Further, physical fatigue is predicted by medical comorbidities, a finding that can be construed as supportive of Whitson et al.'s (2011) study linking exhaustion with poor self-rated health and related poly-medication use. At least, these results suggest that lack of vitality in patients with chronically illnesses can be affected by multiple comorbidities, or even by concurrent multiple medical treatments. Clearly, more clinical studies are needed to determine medical predictors of fatigue.

The current findings associate both form of fatigue symptoms with preoperative anxiety, as an indicator of distress, but not with depression, as found by Whitson et al.'s (2011) elderly survey. As in other cardiac studies (Huffman, Smith, Blais, Januzzi, \& Fricchione, 2008; Lindgren et al., 2008; Rothenbacher, Hahmann, Wusten, Koenig, \& Brenner, 2007), the current data indicate that anxiety, as a preoperative distress indicator, is a stronger predictor of subsequent cardiac outcomes than depression. This finding 
is clinically valuable given the difficulty in obtaining measures of negative emotional states prior to traumatic events. Although anxiety has drawn less research interest than depression (Pignay-Demaria et al., 2003), in studies cardiac patients, elevated anxiety predicted poor quality of life at 4 months after MI (Lane, Carroll, Ring, Beevers, \& Lip, 2000) and increased risks for experiencing CHD, atrial fibrillation, and all-cause mortality (Eaker, Sullivan, Kelly-Hayes, D'Agostino, \& Benjamin, 2005). When combined with our research, the reviewed findings call for more attention to the connection between anxiety and postoperative functioning, as well as the counteracting influences of anxiety and prayer on health.

Our previous prospective research on cardiac patients showed no demographic effects in postoperative levels of depression and anxiety (Ai, Ladd et al., 2010). In this study, however, mental fatigue was more prevalent among men, whereas age influenced physical fatigue at the 30-month follow-up. These gender and age difference suggests that fatigue symptoms and negative effect may have different clinical manifestations and attributes among cardiac patients, though fatigue is frequently considered to be an aspect of depression among physically healthy adults.

A puzzling and unexpected finding is the positive relationship between preoperative secular reverence and postoperative mental fatigue or lack of vitality, despite previously reported buffering effects of secular reverence on length of postoperative hospital stay (Ai, Wink, \& Shearer, 2011; Ai, Wink et al., 2009). It may be that individuals who experienced preoperatively positive spiritual feeling in activities of everyday life found it harder to cope with long-term limitations imposed on their routines at the 30-month follow-up. Alternatively, because the feeling of secular reverence was correlated with age, there might be some unknown factors that altered our findings. Our conjectures on this matter remain speculative, waiting to be tested with new data.

The study is limited by a convenience sample, racial and religious homogeneity of participants; and attrition rates at the follow-up that can bias the findings towards mentally and physically better-off survivors. Also, there is no sufficient poly-medication data available in the STS database. We could only assume that the effect of multiple medical comorbidities may partly support Whitson et al.'s (2011) findings on older patients. However, the prospective finding that prayer coping buffers against mental fatigue implies that it is important for health providers to be attentive to the religionhealth connection through the whole-person approach will enable practitioners to better treat and rehabilitate their older patients, if they broaden their focus of intervention beyond HWB and organ deficits to include positive aspects of EWB.

\section{Acknowledgements}

This work was supported by National Institute on Aging Grant 1 RO3 AGO 15686-01, National Center for Complementary and Alternative Medicine Grant P50 AT00011, and grants from the John Templeton Foundation and Hartford Geriatric Faculty Scholars Program. The opinions expressed in this article are those of the authors and do not necessarily reflect the views of these organizations.

\section{References}

Ai, A. L., Dunkle, R. E., Peterson, C., \& Bolling, S. F. (1998). The role of private prayer in psychosocial recovery among midlife and aged patients following cardiac surgery. Gerontologist, 38, 591601. 
Ai, A. L., Ladd, K. L., Peterson, C., Cook, C., Shearer, M., \& Koenig, H. G. (2010). Long-term adjustment after surviving open-heart surgery: The effect of using prayer for coping replicated in a prospective design. Gerontologist, 50, 798-809.

Ai, A. L., Park, C., Huang, B., Rodgers, W., \& Tice, T. N. (2007). Psychosocial mediation of religious coping: A prospective study of short-term psychological distress after cardiac surgery. Personality and Social Psychology Bulletin, 33, 867-882.

Ai, A. L., Peterson, C., Bolling, S. F., \& Koenig, H. (2002). Private prayer and the optimism of middle-aged and older patients awaiting cardiac surgery. Gerontologist, 42, 70-81.

Ai, A. L., Peterson, C., Bolling, S. F., \& Rodgers, W. (2006). Depression, faith-based coping, and short-term post-operative global functioning in adult and older patients undergoing cardiac surgery. Journal of Psychosomatic Research, 60, 21-28.

Ai, A. L., Peterson, C., Rodgers, W., \& Tice, T. N. (2005). Effects of faith and secular factors on health locus of control in middle-aged and older cardiac patients. Aging and Mental Health, 9, 470-481.

Ai, A. L., Peterson, C., Tice, T. N., Huang, B. C., Rodgers, W., \& Bolling, S. F. (2007). The influence of prayer on mental health among cardiac surgery patients: The role of optimism and acute distress symptoms. Journal of Health Psychology, 12, 580-596.

Ai, A. L., Peterson, C., Tice, T. N., Rodgers, W., Seymour, E. M., \& Bolling, S. F. (2006). Differential effects of faith-based coping on physical and mental fatigue in adult and older cardiac patients. International Journal of Psychiatry in Medicine, 36, 347-361.

Ai, A. L., Rollman, B. L., \& Berger, C. S. (2010). Co-morbid mental health symptoms and heart diseases: Can health care and mental health care professionals collaboratively improve the assessment and management? Health \& Social Work, 35, 27-38.

Ai, A. L., Tice, T. N., Lemieux, C., \& Huang, B. (2011). Modeling the post-9/11 paradox in an existential domain: From deep connection and struggle to posttraumatic stress and growth. Archive for Psychology of Religion, 33, 173-204.

Ai, A. L., Wink, P., \& Shearer, M. (2011). Secular reverence predicts shorter hospital length of stay among middle-aged and older patients following open-heart surgery. Journal of Behavioral Medicine, 34, 532-541.

Ai, A. L., Wink, P., Tice, T. N., Bolling, S. F., Wasin, A., \& Shearer, M. (2009). Prayer and reverence in naturalistic, aesthetic, and socio-moral contexts predicted fewer complications following coronary artery bypass. Journal of Behavioral Medicine, 32, 570-581.

Appels, A., \& Mulder, P. (1988). Excess fatigue as a precursor of myocardial infarction. European Heart Journal, 9, 758-764.

Aristotle (1962). The Nichomachean ethics (M. Oswald, Trans.), Indianapolis, IN: The Bobs-Merrill Company.

Astin, J. A., Shapiro, S. L., Lee, R. A., \& Shapiro, D. H., Jr. (1999). The construct of control in mind-body medicine: Implications for healthcare. Alternative Therapies, 5, 42-47.

Baron, R. M., \& Kenny, D. A. (1986). The moderator-mediator variable distinction in social psychological research: Conceptual, strategic, and statistical considerations. Journal of Personality and Social Psychology, 51, 1173-1182.

Barth, J., Schumacher, M., \& Herrmann-Lingen, C. (2004). Depression as a risk factor for mortality in patients with coronary heart disease: A meta-analysis. Psychosomatic Medicine, 66, 802813.

Begun, Y. (1997). Quoted in M. C. Luzzatto, The way of God [ca. 1734] (6th rev. ed.). Trans. by A. Kaplan. Jerusalem: Feldheim Publishers.

Carroll, D., Phillips, A. C., Hunt, K., \& Der, G. (2007). Symptoms of depression and cardiovascular reactions to acute psychological stress: Evidence from a population study. Biological Psychology, 75, 68-74.

Chalder, T., Berelowitz, G., Pawlikowska, T., Watts, L., Wessely, S., Wright, D., \& Wallace, E. P. (1993). Development of a fatigue scale. Journal of Psychosomatic Research, 37, 147153. 
Chatters, L. M., Levin, J. S., \& Taylor, R. J. (1992). Antecedents and dimensions of religious involvement among older Black adults. Journal of Gerontology: Social Sciences, 47B, S269S278.

Cohen, A. B., Hall, D. E., Koenig, H. G., Meador, K. G. (2005). Social versus individual motivation: Implications for normative definitions of religious motivations. Personality and Social Psychology Review, 9, 48-61.

Contrada, R. J., Goyal, T. M., Cather, C., Rafalson, L., Idler, E. L., \& Krause, T. (2004). Psychosocial factors in outcomes of heart surgery: The impact of religious involvement and depressive symptoms. Health Psychology, 23, 227-238.

De Meirleir, K., \& McGregor, N. (2003). Chronic fatigue syndrome guidelines. Journal of Chronic Fatigue Syndrome, 11, 1-6.

Duits, A. A., Boeke, S., Taamms, M. A., Passchier, J., \& Erdman, R. A. M. (1997). Prediction of quality of life after coronary artery bypass graft surgery: A review and evaluation of multiple, recent studies. Psychosomatic Medicine, 59, 257-268.

Eaker, E. D., Sullivan, L. M., Kelly-Hayes, M., D'Agostino, R. B. Sr., \& Benjamin, E. J. (2005). Tension and anxiety and the prediction of the 10-year incidence of coronary heart disease, atrial fibrillation, and total mortality: The Framingham Offspring Study. Psychosomatic Medicine, 67, 692-696.

Hägglund, L., Boman, K., Lundman, B., \& Brulin, C. (2008). Depression among elderly people with and without heart failure, managed in a primary healthcare setting. Scandinavian Journal of Caring Sciences, 22, 376-382.

Helgeson, V. S., \& Fritz, H. L. (1999). Cognitive adaptation as a predictor of new coronary events after percutaneous transluminal coronary angioplasty. Psychosomatic medicine, 61, 488-495.

Hofer, S., Lim, L., Guyatt, G., \& Oldridge, N. (2004). The MacNew heart disease healthrelated quality of life instrument: A summary. Health and Quality of Life Outcomes, 2, 3. doi:10.1186/1477-7525-2-3

Huffman, J. C., Smith, F. A., Blais, M. A., Januzzi, J. L., \& Fricchione, G. L. (2008). Anxiety, independent of depressive symptoms, is associated with in-hospital cardiac complications after acute myocardial infarction. Journal of Psychosomatic Research, 65, 557-563.

James, W. (1901/1958). The varieties of religious experience: A study in buman nature. New York: The New American Library.

Janszky, I., Lekander, M., Blom, M., Georgiades, A., \& Ahnve, S. (2005). Self-rated health and vital exhaustion, but not depression, is related to inflammation in women with coronary heart disease. Brain, Behavior, and Immunity, 19, 555-563.

Jason, L. A., Wagner, L., Taylor, R., Ropacki, M. T., Shlaes, J., Ferrari, J. R., ... Stenzel, C.(1995). Chronic fatigue syndrome: A new challenge for health care professionals. Journal of Community Psychology, 23, 143-164.

Koenig, H. G., McCullough, M. E., \& Larson, D. B. (2001). Handbook of religion and health. New York: Oxford University Press.

Koertge, J., Al-Khalili, F., Ahnve, S., Janszky, I., Svane, B. \& Schenck-Gustafsson, K. (2002). Cortisol and vital exhaustion in relation to significant coronary artery stenosis in middle-aged women with acute coronary syndrome. Psychoneuroendocrinology, 27, 893-906.

Kop, W. J., Appels, A., Mendes de Leon, C. F., De Swart, H. B., \& Bär, F. W. (1993). Vital exhaustion predicts new cardiac events after successful coronary angioplasty. Psychosomatic Medicine, $56,281-287$.

Kwaijtaal, M., Van Der Ven, A. J., Van Diest, R., Bruggeman, C. A., Bär, F. W., Calandra, T., ... McPherson, C. A. (2000). Destabilizing effects of mental stress on ventricular arrhythmias in patients with implantable cardioverter-defibrillators. Circulation, 101, 158-164.

Ladd, K. L., Ladd, M. L., Ashbaugh, P., Trnka, D., Harner, J., St. Pierre, K., \& Swanson, T. (2007). Inward, outward, upward prayer and personal character. Research in the Social Scientific Study of Religion, 18, 209-231.

Ladd, K. L., \& Spilka, B. (2002). Inward, outward, upward: Cognitive aspects of prayer. Journal for the Scientific Study of Religion, 41, 475-484. 
Ladd, K. L., \& Spilka, B. (2006). Inward, outward, upward prayer: Scale reliability and validation. Journal for the Scientific Study of Religion, 45, 233-251.

Lane, D., Carroll, D., Ring, C., Beevers, D. G., \& Lip, G. Y. (2000). Effects of depression and anxiety on mortality and quality of life 4 months after myocardial infarction. Journal of Psychosomatic Research, 49, 229-238.

Levin, J. (2004). Prayer, love, and transcendence: An epidemiologic perspective. In K. W. Schaie, N. Krause, \& A. Booth (Eds.), Religious influences on bealth and well-being in the elderly (pp. 69-95). New York: Springer Publishing Company.

Lindgren, T. G., Fukuoka, Y., Rankin, S. H., Cooper, B. A., Carroll, D., \& Munn, Y. L. (2008). Cluster analysis of elderly cardiac patients' prehospital symptomatology. Nursing Research, 57, 14-23.

McIntosh, D., \& Spilka, B. (1990). Religion and physical health: The role of personal faith and control beliefs. Research in the Social Scientific Study of Religion, 2, 167-194.

Miller, W. R., \& Thoresen, C. E. (2003). Spirituality, religion, and health: An emerging research field. American Psychologist, 58, 24-35.

Moser, D. K., Riegel, B., McKinley, S., Doering, L. V., Meischke, H., Heo, S., . . Dracup, K. (2009). The Control Attitudes Scale-Revised: Psychometric evaluation in three groups of patients with cardiac illness. Nursing Research, 58, 42-51.

Oman, D., \& Thoresen, C. E. (2005). Do religion and spirituality influence health? In R. F. Paloutzian, \& C. L. Park (Eds.), Handbook of the psychology of religion and spirituality. New York: Guilford Press.

Oxman, T. E., Freeman, D. H., \& Manheimer, E. D. (1995). Lack of social participation or religious strength and comfort as risk factors for death after cardiac surgery in the elderly. Psychosomatic Medicine, 57, 5-15.

Pargament, K. I., Smith, B. W., Koenig, H. G., \& Perez, L. (1998). Patterns of positive and negative religious coping with major life stressors. Journal for the Scientific Study of Religion, 37, $710-724$.

Pignay-Demaria, V., Lesperance, F., Demaria, R. G., Frasure-Smith, N., \& Perrault, L. P. (2003). Depression and anxiety and outcomes of coronary artery bypass surgery. Annals of Thoracic Surgery, 75, 314-321.

Radloff, L. S. (1977). The CES-D scale: A self-report depression scale for research in the general population. Applied Psychological Measurement, 1, 385-401.

Rothenbacher, D., Hahmann, H., Wusten, B., Koenig, W., \& Brenner, H. (2007). Symptoms of anxiety and depression in patients with stable coronary heart disease: Prognostic value and consideration of pathogenetic links. European Journal of Cardiovascular Prevention and Rehabilitation, 14, 547-554.

Ryan, R. M., \& Deci, E. L. (2000). Self-determination theory and the facilitation of intrinsic motivation, social development, and well-being. American Psychologists, 55, 68-78.

Ryan, R. M., \& Deci, E. L. (2001). On happiness and human potentials: A review of research on hedonic and eudaimonic well-being. Annual Review of Psychology, 52, 141-66.

Ryan, R. M., \& Frederick, C. M. (1997). On energy, personality and health: Subjective vitality as a dynamic reflection of well-being. Journal of Personality, 65, 529-565.

Ryff, C. D., Singer, B., Love, G. D., \& Essex, M. J. (1998). Resilience in adulthood and later life: Defining features and dynamic processes. In J. Lomranz (Ed.), Handbook of aging and mental bealth: An integrative approach (pp. 69-96). New York, NY: Plenum Press.

Ryff, C. D., \& Springer, B. H. (2003). Flourishing under fire: Resilience as a prototype of challenged thriving. In C. L. M. Keyes \& J. Haidt (Eds.). Flourishing: Positive psychology and the life well-lived (pp. 15-36). Washington, DC: American Psychological Association.

Scheier, M. F., \& Carver, C. S. (1985). Optimism, coping, and health: Assessment and implications of generalized outcome expectancies. Health Psychology, 4, 219-247.

Smith, O. R. F., Gidron, Y., Kupper, N., Winter, J. B., \& Denollet, J. (2009). Vital exhaustion in chronic heart failure: Symptom profiles and clinical outcome. Journal of Psychosomatic Research, 66, 195-201. 
Snyder, C. R., Harris, C., Anderson, J. R., Holleran, S. A., Irving, L. M., Sigmon, S. T. (1991). The will and the ways: Development and validation of an individual-differences measure of hope. Journal of Personality and Social Psychology, 60, 570-585.

Spielberger, C. D. (1983). Manual for the State-Trait Anxiety Inventory (Form Y). Palo Alto, CA: Consulting Psychologists Press.

Stanek, E. J., Oates, M. B., McGhan, W. F., Denofrio, D., \& Loh, E. (2000). Preferences for treatment outcomes in patients with heart failure: Symptoms versus survival. Journal of Cardiac Failure, $6,225-232$.

Wallston, K. A., Wallston, B. S., \& DeVellis, R. (1978). Development of the Multidimensional Health Locus of Control (MHLC) scales. Health Education Monographs, 6, 160-170.

Weinstein, S. E., Quigley, K. S., \& Mordkoff, J. T. (2002). Influence of control and physical effort on cardiovascular reactivity to a video game task. Psychophysiology, 39, 591-598.

Whitson, H. E., O'Mare, A. M., Chaves, P. H. M., Zakai, N. A., \& Newman, A. B. (2011). Patterns and predictors of recovery from exhaustion in older adults: The cardiovascular health study. Journal of American Geriatric Society, 59, 207-213.

Wilks, S. E., \& Vonk, M. E. (2008). Coping through private prayer: Mediating burden and resiliency among Alzheimer's caregivers. Journal of Gerontological Social Work, 50, 113-131.

Zimet, G. D., Powell, S. S., Farley, G. K., Werkman, S., \& Berkoff, K. A. (1990). Psychometric characteristics of the Multidimensional Scale of Perceived Social Support. Journal of Personality Assessment, 55, 610-617. 